\title{
A Schematic Research Guide Heuristic Model: Research Methodology Made Easy
}

\author{
Simeon Abel Igah \\ Research Scholar (Ph. D.) \\ Department of Business Studies \\ Faculty of Management Sciences, \\ Ignatius Ajuru University of Education, Port Harcourt, \\ Nigeria
}

\begin{abstract}
The objective of this research heuristic model is to give a outlook on how to carry out a research, from start to finish. This is not just a flow chart; it is a comprehensive research-tackling-guide-model that directs the researcher where to go, what next to do or achieve at any point on the schematic research diagram. Most researchers get confused on what to do, even at the point of discovering the knowledge and research gap. This work paves the way on how the researcher should begin the research work from the start point to the finish point.
\end{abstract}

Keywords: Schematic, Research Guide, Model, Research.

\section{INTRODUCTION}

The complexities associated with carrying out a dutiful research need a heuristic model to make the entire research work simple and interesting. It is on this ground that the author came up with this classical-fit-for all social science research heuristic model. The user need carefully follow the stage by stage steps of the schematic diagram. Each stage of the heuristic model is explained below the diagram to have a full grasp of the flow of the research activities.

\section{MATHEMATICAL APPROACH TO THE DETERMINATION OF THE OBJECTIVES, HYPOTHESES, RESEARCH QUESTIONS AND SUB-RESEARCH QUESTION OF THE PROJECT}

(1) Determination of Research Objectives

The number of Factor/Item Dimensions multiplied by the Dependent variable plus the measures of the Moderating Variables plus the Suppressor Variables, if any = total research objectives

(2) Determination of Research Hypothesis

The number of Factor/Item Dimensions multiplied by the measures plus the measures of the Moderating Variables of the Suppressor Variables, if any = Total Research Hypotheses.

(3) Determination of Research Questions

The total number of research objectives multiplied by one $=$ Total Research Questions

(4) Determination of Total Sub-Research Questions

a. Minimum of the total number of hypotheses divided by 2 (if it is a correlational study)

b. Minimum of the total number of hypotheses (if not a correlational). 
International Journal of Advances in Scientific Research and Engineering (ijasre), Vol 8 (1), January -2022

\section{COMPREHENSIVE RESEARCH HEURISTIC MODEL}

This heuristic model is demonstrated by the use of arrows. These arrows indicate one step or stage after the other. A particular stage or step can lead to two or more steps or stages. The colourization of arrows is just for the purpose of differentiation.

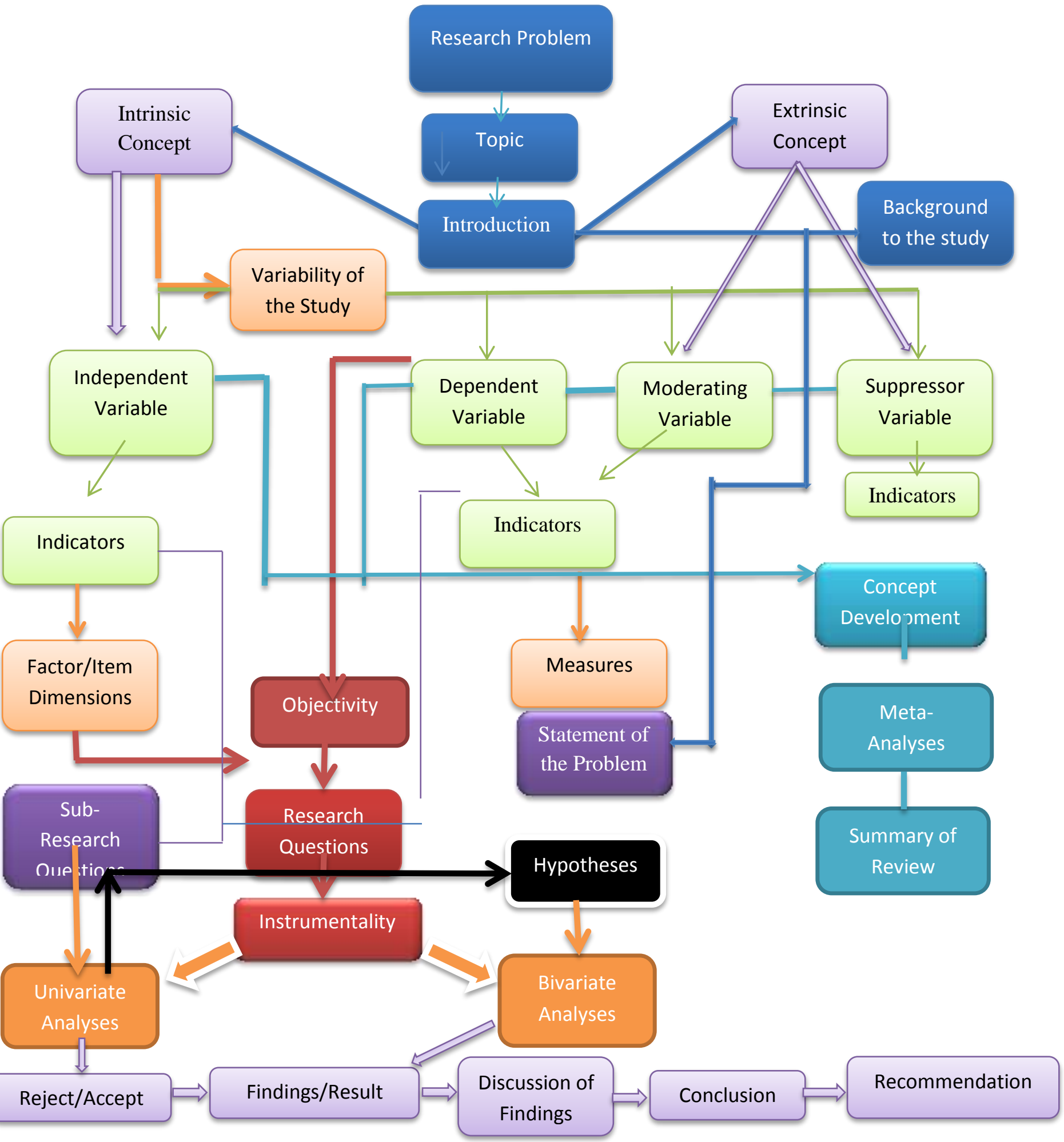

Figure1. Comprehensive Research Heuristic Model

Source: Researcher's Schematic Research Model, 2021 


\section{DESCRIPTION OF TERMNOLOGY}

1. Research Problem: - This is the take-off or departure point for the entire research. It is the point at which the researcher discovers the problem.

2. Topic: - This is the theme given to the research problem discovered. It is called the topic or title of the research. You can call it the topic or the research problem. Sometimes, it is used interchangeably.

3. Introduction: - This is where the researcher explains what the research is all about. The various stages of the research are briefly explained. The tense used is the future tense. This is because the introduction gives you the futuristic account of the research.

4. Background to the Study: - This is where the researcher explains three important things - (1) the relevance of the default or research or dependent variable to the individual person, family, organization, industry and to the globe at large. (2) the dependence of the research variable or the dependent variable to the explanatory or independent variable or the default variable (3) the deficiency and inconsistency of the default variable.

5. Statement of the Problem: - This explains the likely challenges that could be posed to the individual, family, organization, industry and to the world in general, if there is no fair mix between the independent and the dependent variables

6. Intrinsic Concept: - This involves christening the research topic on the problem discovered

7. Extrinsic Concept: - This involves christening the research topic beyond the problem discovered.

8. Variability of the Study: - This is the conceptualization of variables for the study.

9. Independent Variable: - This is the variable that impacts on the dependent variable, It Determines what happens to the dependent variable. it forms part of the intrinsic concept. It is also called the explanatory variable or default variable.

10. Dependent Variable: - This is the variable that responds to the changes in the independent variable. It is part of the intrinsic concept. It is also called the research variable.

11. Moderating Variable: - This is a variable upon which the independent and dependent variable plays out. In most cases, the moderating variable positively influences the relationship between the independent and the dependent variable. It forms part of the extrinsic concept.

12. Suppressor Variable: - This is a variable upon which the independent and dependent variable plays out. In most cases, the suppressor variable negatively influences the relationship between the independent and the dependent variable. It forms part of the extrinsic concept. It works in the opposite direction of the moderating variable.

13. Indicators: - These are what give the variables definition. It is from the indicators the dimensions and measures are formed. The sub-research questions are formed from the indicators of the dimensions and measures as it relates to correlational research.

14. Item/Factor Dimension: - These are what represent the independent variable through the indicators. The direct dimension of an independent variable is called a factor dimension, while dimension under dimensions is called item dimension.

15. Measures: - These are what represent the dependent, moderating and the suppressor variables through their indicators.

16. Concept Development: - This is the point at which each of the concepts (variables) is explained.

17. Meta-Analysis: - This is when the ideas of various authors on the concepts or variables are compared

18. Summary of Review: - This is the over view or the summary of the concept development

19. Objectivity: - This explains the research objective. It is the very reason for carrying out the research work, in the first place.

20. Research Question: - These are questions to be answered by the researcher. They are derived from the objectives of the study.

21. Sub-Research Question: These are questions to be answered by the research respondents. It's from the answers to the subresearch question that the researcher draws answers to the research questions. The questions should be asked correlationally, using the indicators of the sociometric variables, dimensions and measures, if it is a correlational study. This means that the sub-research questions must be framed based on the operational framework of the variables, factor/item dimension and measures, using inclusively their respective indicators. If it is an econometric study, you may not use a correlational questioning pattern. This is best fit using a secondary data. 
22. Hypotheses: - These are tentative conclusions from the univariate analyses made, which are drawn from the opinions or answers offered by the research respondents.

23. Instrumentality: - This is the medium used to source for information from the research respondents as answers to the subresearch questions. If the answers are got at one sweep, it is called a cross-sectional survey design. If the answers are got at different times from the same respondents it is called longitudinal survey design.

24. Univariate Analysis: - This is the analysis done on the information got from the research respondents. This analysis is on the frequencies score, representing the opinions of the research respondents, based on the Likert scaling used by the researcher in the questionnaire. What you need first is to compute the pre-determined average mean, which stands as the effect size. If it is a 5-point Likert scaling as: Strongly Agree, Agree, No-idea, Disagree and Strongly Disagree, you should add up the 5-point Likert Scaling and divide by 5. Example: $1+2+3+4+5=15 / 5=3$. The effect size or average predetermined mean is 3 . Any computed mean from the frequencies of the 5-point Likert scaling, as opined by the research respondents, would be compared with the pre-determined mean ( effect size). If the pre-determined mean is greater than the computed mean, the respondents' opinion is accepted and if the reverse, the general opinions of the research respondents are rejected.

25. Bivariate Analysis: - This is the analysis done on the tentative conclusion as hypotheses to ascertain whether the opinions of the research respondents were by chance, upon which the rejection or acceptance in the univariate analysis was based. This can be done using the simple linear regression analysis approach, if each measure is analysed alongside each factor dimension or item dimension. It is a multiple linear regression analysis approach, if each of the measure of the dependent variable is analysed alongside all the factor/item dimensions at the same time.

26. Reject/Accept: - This assertion is made after comparing the pre-determined mean against the computed mean. If the predetermined mean is higher than the computed mean, you accept the opinion of the research respondents as positive or negative answer to the sub-research question and if the pre-determined mean is lower than the computed mean, you reject.

27. Findings/Results: - This is the outcome of the hypotheses testing. Whatever outcome that comes out of the analysis is accepted as scientific judgement.

28. Discussion of Findings: - This is the point of comparing the findings in your hypotheses testing and that of other related work in your empirical review or ideas of other authorities cited in your work.

29. Conclusion: - This is the point where the researcher explains what has transpired in the research, following what the introduction of the study spelt out. The tense used in the conclusion is always the past tense. This is because the conclusion tells you the historical account of the research. Introduction, conclusion and abstract have the same purposes. Their differences are based on tenses. Introduction uses the future tense, the conclusion uses the past tense and the abstract uses the past tense too. However, the abstract is the executive summary of the conclusion.

30. Recommendation: - This is the expert advice of the researcher, strictly based on the outcome or findings of the analyses. There should be no extraneous advice from the findings that should be entertained.

\section{CONCLUSION}

The significance of this Schematic-Research-Guide Model is to assist researchers who find research work confusing and complex. Research work is made easy by way of the application of this schematic- research guide model. At least 30 items or subjects were explained in this work that would help researchers have a smooth sail on their research work. The researcher presented a very informative and comprehensive a Schematic Research Heuristic Model.

\section{REFERENCES}

1. Chikwe, J. E. (2011). Corporate Social Responsibility and Organizational Effectiveness. A Ph.D. Thesis, University of Science and Technology, Port Harcourt. Unpublished.

2. Robert, S. M. (2019). How are variables measured? Retrieved from: http://www.indiana.edu/ educy520/sec5982/week_3/measurement_rsm.pdf-Measurement-2

3. Susan, C. L. (2017). Variables and Hypotheses. Retrieved from: http://myweb.fsu.edu/slosh/MethodsGuide2.html. Accessed: 2018 
International Journal of Advances in Scientific Research and Engineering (ijasre), Vol 8 (1), January -2022

4. Racidon Bernarte (2017). Concepts, Variables, Indicators and Measurements. Retrieved from: http://myweb.fsu.edu/slosh/MethodsGuide2.html. Accessed: 2019

5. Statistics Solutions (2013). Hypothesis Testing. Retrieved from: https://www.statisticssolutions.com/hypothesis-testing/. Accessed: 2019

6. Statistics Solution (2019). Assumptions of Multiple Linear Regression. Retrieved from: https://www.statisticssolutions.com/assumptions-of-multiple-linear-regression/. Accessed: February, 2019

7. Wolfram Mathworld (2019). Probability, Statistics and Statistical Tests. Retrieved from: http://mathworld.wolfram.com/HypothesisTesting.html. Accessed: 2018

Author's Contact: brotherabel1@gmail.com 